FARIA, E.C.D.; CARRIJO, O.A.; MORETTI, C.L. Avaliação de fontes de cálcio na cultura do melão tipo 'Gália' sob cultivo protegido. Horticultura Brasileira, Brasília, v.22, n.3, p.557-561, jul-set 2004.

\title{
Avaliação de fontes de cálcio na cultura do melão tipo 'Gália' sob cultivo protegido $^{1}$
}

\author{
Eva Cintra D. de Faria ${ }^{2}$; Osmar A. Carrijo ${ }^{3}$; Celso L. Moretti ${ }^{4}$ \\ ${ }^{2}$ AGENCIARURAL, Av. Miguel João, 27, Centro, 75.020-360 Anápolis-GO; E-mail: evacintra@ hotmail.com; ${ }^{3}$ Pesquisador PhD., \\ Embrapa Hortaliças e Prof. UnB, C. Postal 218, 70.359-970 Brasília-DF; E-mail: carrijo@ cnph.embrapa.br ${ }^{4}$ Pesquisador Dr., Embrapa \\ Hortaliças. C. Postal 218, 70.359-970 Brasília-DF.
}

\section{RESUMO}

Um experimento com a cultura de Melão (Cucumis melo L. var. reticulatus), do tipo Gália, híbrido Galileo foi conduzido sob cultivo protegido, em vasos, na Embrapa Hortaliças, em Brasília-DF, de setembro a dezembro de 2001. Foram avaliadas 5 formas de aplicação de cálcio (calagem, calagem mais fertirrigação com nitrato de cálcio, cálcio tamponado, cálcio quelatizado e cloreto de cálcio) além do tratamento controle, sem cálcio. O delineamento experimental foi de blocos ao acaso com seis tratamentos e seis repetições e parcelas com seis plantas. Não houve diferença estatística entre os tratamentos. No entanto, uma análise de contrastes mostrou um aumento de $26 \%$ em peso $\left(\mathrm{kg} \mathrm{m}^{-2}\right)$ e $21 \%$ em número de frutos comerciais resultante da aplicação de cálcio, indicando a importância da aplicação do nutriente em pré-plantio e/ou fertirrigação para solos com saturação de bases (V\%) abaixo de $70 \%$. Constatou-se aumento de $30 \%$ na produtividade e de $27 \%$ no número de frutos comerciais com o uso da fertirrigação. Houve aumento de $23 \%$ no número de frutos comerciais nos tratamentos com cálcio e com calagem $(3,52$ frutos $\mathrm{m}^{-2}$ ), em relação ao tratamento onde utilizou-se apenas calagem $\left(2,87\right.$ frutos $\left.\mathrm{m}^{-2}\right)$. Não houve efeito dos tratamentos sobre os pesos médios dos frutos. Os tratamentos fertirrigados com nitrato de cálcio e cloreto de cálcio apresentaram maior eficiência econômica. Não houve efeito significativo dos tratamentos sobre a espessura, teores de sólidos solúveis totais (Brix), acidez total titulável (ATT) e relação Brix/ATT. Conclui-se que há a necessidade de aplicação de cálcio no meloeiro sob cultivo protegido para solos com saturação de base abaixo de $70 \%$ e que a calagem mais fertirrigação com cálcio foi mais efetiva do que só a calagem. O uso do nitrato ou do cloreto de cálcio em fertirrigação apresentou maior rentabilidade do que a calagem ou calagem mais fertirrigação com cálcio tamponado ou cálcio quelatizado.

Palavras-chave: Cucumis melo L. var. reticulatus, calagem, adubação, gotejamento, fertirrigação, saturação de bases, qualidade do fruto.

\begin{abstract}
Comparative analysis of calcium sources in greenhouse 'Galia' muskmelon

'Galia' muskmelons, Galileo hybrid, were grown at Embrapa Hortaliças in Brasilia, Brazil, in a greenhouse in pots, from September to December 2001. Five calcium treatments were evaluated (liming and liming plus fertigation with calcium nitrate, calcium buffered, calcium chelates and calcium chloride), besides the control without calcium $(\mathrm{Ca})$. The experimental design was of randomized blocks with 6 treatments, 4 replications and 6 plants per plot. Overall calcium application increased marketable yield $\left(\mathrm{kg} \mathrm{m}^{-2}\right)$ by $26 \%$ and the number of fruits by $21 \%$. These results indicated the need of $\mathrm{Ca}$ fertilization in soils with base saturation lower than $70 \%$. Liming plus calcium fertigation increased yield and the number of marketable fruits by $30 \%$ and $27 \%$, respectively. Thus, Ca fertigation was more effective than liming. Fertigation with calcium nitrate and calcium chloride presented the highest profitability. No effect was observed on the average fruit weight. No significant effects on treatments were obtained for pulp thickness, soluble solids content (Brix), total titratable acidity (TTA) and Brix/TTA ratio. In conclusion, Ca must be applied to greenhouse muskmelon for soils with base saturation lower than $70 \%$. Liming plus Ca fertigation was more profitable than only liming. Fertigation of Ca-nitrate or $\mathrm{Ca}$-chloride was more profitable than liming plus $\mathrm{Ca}$ treatments (liming and liming plus fertigation with Ca-buffered or Ca-chelates).
\end{abstract}

Keywords: Cucumis melo L. var. reticulatus, liming, fertilizers, drip irrigation, fertigation, base saturation, fruit quality.

\section{(Recebido para publicação em 16 de fevereiro de 2003 e aceito em 25 de abril de 2004)}

$\mathrm{O}$ melão tipo Gália produz frutos reticulados e exalam aroma característico. O híbrido Galileo possui casca verde (que muda para amarela quando o fruto amadurece), polpa brancoesverdeada, reticulado, teor de sólidos solúveis elevado e massa média entre 0,7 e $1,6 \mathrm{~kg}$. Este tipo de melão tem sido indicado para cultivo protegido, dada a exigência do mercado para frutos com alta qualidade. Neste sistema de produção, a irrigação por gotejamento é a mais utilizada por propiciar alta eficiência, ser de fácil automação e possibilitar a prática da fertirrigação. Trabalhando com melão tipo Gália, Hernandez e Aso (1991) verificaram que os tratamentos em que foram distribuídos fertilizantes de base e em fertirrigação foram mais efetivos que aqueles onde todos os fer- tilizantes foram aplicados ao solo antes do transplantio.

$\mathrm{O}$ meloeiro é bastante exigente em cálcio $(\mathrm{Ca})$, sendo um dos nutrientes mais absorvidos por esta cultura (Canato et al., 2001). Os níveis foliares de cálcio variam de 2 a $7 \%$ e tendem a aumentar durante o ciclo de cultivo (Cantón, 1999). O cálcio é importante para a obtenção de frutos de boa quali-

\footnotetext{
${ }^{1}$ Parte da dissertação de Mestrado do primeiro autor submetido à Universidade de Brasília.
} 
dade tanto na aparência visual com redução da podridão apical, como no aumento da vida de prateleira (Lester, 1996).

A qualidade dos frutos de meloeiro é afetada pela fonte de cálcio utilizada e os frutos das plantas que receberam a aplicação de cloreto de cálcio $\left(\mathrm{CaCl}_{2}\right)$ eram mais perecíveis na armazenagem (Mallick et al., 1984). Por outro lado o quelato de cálcio e boro pulverizados em pré-colheita propiciaram maiores índices de textura e espessura de polpa dos frutos do que cloreto de cálcio (Pereira, 1997). Alguns autores relatam que a calagem por si só é capaz de suprir toda a necessidade de cálcio das culturas. No entanto, os produtores desta hortaliça fazem aplicação desse nutriente em cobertura ou em fertirrigação mesmo após a calagem, embora não tenha sido encontrado trabalhos técnicos científicos que comprovem a eficiência desta prática no melão tipo Gália. O presente trabalho teve por objetivo avaliar o efeito do cálcio aplicado em pré-plantio e o efeito das fontes disponíveis para fertirrigação da cultura de melão tipo gália, sob cultivo protegido.

\section{MATERIAL E MÉTODOS}

O trabalho foi conduzido na área experimental da Embrapa Hortaliças, em Brasília-DF, em casa de vegetação com $50 \mathrm{~m}$ de comprimento e $8 \mathrm{~m}$ de largura, tipo teto em arco, coberta com filme de polietileno de $150 \mu \mathrm{m}$ de espessura e lateralmente envolta com o mesmo material da cobertura até a altura de $1 \mathrm{~m}$ do nível do solo. Durante os meses de setembro a dezembro de 2001, época da condução do experimento, a temperatura mínima foi de $16,8^{\circ} \mathrm{C}$ e a máxima de $37^{\circ} \mathrm{C}$ no interior da casa de vegetação, enquanto a umidade relativa do ar variou de $28 \%$ em setembro a $89 \%$ em novembro.

Utilizou-se melão (Cucumis melo L. var. reticulatus), do tipo Gália, híbrido Galileo. As mudas foram produzidas em bandeja de poliestireno de 72 células utilizando substrato comercial e transplantadas aos 15 dias após a semeadura quando as mudas apresentavam uma a duas folhas definitivas.

$\mathrm{O}$ experimento foi conduzido em vasos de 10 litros contendo substrato preparado com a mistura de 3 partes de solo para 1 parte de casca de arroz parcialmente carbonizada e calcário calcítico "filler" para elevar a saturação de bases para 70\% (Silva et al, 2000). A mistura foi esterilizada por autoclavagem. $\mathrm{O}$ tratamento testemunha não recebeu calcário. $\mathrm{O}$ solo utilizado na preparação do substrato era da classe textural franco-argilo-siltoso, com condutividade elétrica $(1: 2,5)$ de $0,05 \mathrm{dS}$ $\mathrm{m}^{-1}, \mathrm{pH}$ em água de 4,95 e um teor de matéria orgânica de $1,9 \mathrm{~g} \mathrm{dm}^{-3}$. Os teores de fósforo $(\mathrm{P})$ e potássio $(\mathrm{K})$ foram respectivamente 5,2 e $190,0 \mathrm{mg} \mathrm{dm}^{-3}$ enquanto que o de cálcio $(\mathrm{Ca})$ foi $3,2 \mathrm{e}$ o de magnésio $(\mathrm{Mg})$ 1,9 cmol. $\mathrm{dm}^{-3}$. Os micronutrientes cobre $(\mathrm{Cu})$, ferro $(\mathrm{Fe})$, zinco ( $\mathrm{Zn})$ e manganês (Mn) apresentaram, respectivamente, os seguintes valores: 0,$2 ; 18,0 ; 0,35$ e $14,4 \mathrm{mg} \mathrm{dm}^{-3}$.

O delineamento experimental foi de blocos ao acaso com 6 tratamentos, calagem, testemunha (sem cálcio) e com calagem mais quatro fontes cálcio em fertirrigação na dose de $80 \mathrm{~kg} \mathrm{~m}^{-2}$ e 6 repetições. As fontes de cálcio utilizadas na fertirrigação foram: nitrato de cálcio, cálcio tamponado (CAL 40²), cálcio quelatizado (CALBIT*) e cloreto de cálcio. A parcela experimental foi constituída por 6 plantas em linhas duplas com espaçamento de $0,5 \mathrm{~m}$ entre linhas, 0,4 m entre plantas e 1,0 $\mathrm{m}$ entre cada duas linhas. Toda a parcela foi considerada como útil tendo uma área total de $1,8 \mathrm{~m}^{2}$.

As irrigações foram diárias e por gotejamento com emissor individual por planta e vazão média de $2,14 \mathrm{~L} \mathrm{~h}^{-1}$. O controle do teor de água no solo foi feito com tensiômetros mantendo-se o potencial da água do solo a $10 \mathrm{~cm}$ de profundidade em torno de $-9 \mathrm{kPa}$ até 27 dias após o plantio. De 28 a 56 dias foi de $-11 \mathrm{kPa}$ à profundidade de $15 \mathrm{~cm}$. A quantidade de água fornecida para as plantas variou de 140 a $320 \mathrm{ml}$ planta dia $^{-1}$, com uma média de $183 \mathrm{ml}$ de 28 a 56 dias após o plantio.
As plantas foram conduzidas com uma única haste na vertical, tutoradas com telas e desbrotas até o $11^{\circ}$ entrenó. Nos entrenós $12^{\circ}, 13^{\circ}$ e $14^{\circ}$ foram deixadas hastes secundárias, onde apareceram as flores hermafroditas (futuros frutos). As hastes secundárias foram podadas após a primeira folha depois do fruto. Todos os brotos foram retirados até o vigésimo entrenó da haste principal. Nos entrenós $21^{\circ}, 22^{\circ}$ e $23^{\circ}$, cresceram hastes secundárias e neste ponto foi feita a capação da planta (Brandão e Vasconcelos, 1999). A polinização foi feita naturalmente por insetos, principalmente abelhas, e os tratos fitossanitários foram os recomendados para a cultura.

A quantidade de fósforo utilizada $\left(100 \mathrm{~kg} \mathrm{ha}^{-1}\right)$ foi definida com base nos resultados da análise do solo (Pereira e Souza, 1999) aplicando $40 \%$ em préplantio e $60 \%$ em fertirrigação. Os macronutrientes NK foram parcelados segundo as curvas de absorção (BarYosef, 1999) e aplicados em fertirrigações semanais em um total de $151 \mathrm{~kg} \mathrm{ha}^{-1}$ e $384,5 \mathrm{~kg} \mathrm{ha}^{-1}$, respectivamente. A quantidade de cálcio aplicada em fertirrigação foi de $80 \mathrm{~kg} \mathrm{ha}^{-1}$ e a sua distribuição foi segundo a curva de absorção deste nutriente para a cultura (Rincon et al., 1998). A relação Ca:Mg utilizada foi de 3:1, considerada a mais adequada para a cultura do melão por Silva (2000).

Utilizou-se $2 / 3$ da adubação nitrogenada na forma nítrica e 1/3 na forma amídica (Carrijo et al, 2001), usando o nitrato de cálcio e o nitrato duplo de potássio como fontes nítricas e a uréia como fonte amídica. As fontes de fósforo foram o fosfato monopotássico (MKP) e o ácido fosfórico. O potássio foi balanceado com sulfato de potássio. A solução de micronutrientes foi preparada com $10 \mathrm{~g}$ de sulfato de zinco, $30 \mathrm{~g}$ de bórax e $12 \mathrm{~g}$ de sulfato de cobre, aplicando $280 \mathrm{ml}$ da solução por semana para um total de 1000 plantas (Andrade e Gontijo, 1999).

Para a determinação dos teores de macro e micronutrientes foi coletada a quinta folha, a partir da gema apical da

\footnotetext{
${ }^{2}$ A referência a marcas comerciais não representa endosso dos autores a esses produtos.
} 
haste principal, e preparadas amostras compostas de 15 folhas por tratamento (Miyazama et al., 1999). As coletas foram no florescimento (55 dias após o transplantio) e na maturação dos frutos (91 dias após o transplantio).

Foram realizadas duas colheitas aos 98 e 103 dias após o transplantio (DAT). Foram considerados fruto comercializáveis os maiores ou iguais ao tipo 9, ou seja, aqueles com peso superior a 550 gramas (Filgueiras et al., 2000). Foram avaliados o peso, número e peso médio de frutos comerciais, as características relacionadas a qualidade: espessura da polpa, firmeza, acidez total titulável (ATT) e sólidos solúveis totais ( ${ }^{\circ}$ Brix), os teores de macro e micronutrientes nas folhas, e a rentabilidade. Apesar de não ser objetivo do trabalho, foi realizada uma análise econômica nos resultados do experimento, conforme metodologia descrita por Perrin et al. (1976).

Os frutos foram colhidos nos estágios de maturação III (frutos com pedúnculo em início de abscisão), IV (fruto com pedúnculo totalmente rachado) e V (fruto sem pedúnculo), segundo classificação de Menezes (1996). Foram utilizados 12 frutos por tratamento selecionados ao acaso para as análises de qualidade na pós-colheita.

\section{RESULTADOS E DISCUSSÃO}

Não houve diferença entre os tratamentos (Tabela 1). No entanto, como os resultados mostraram que os tratamentos fertirrigados com cálcio e com calagem apresentaram valores absolutos maiores que a testemunha e até mesmo que somente com calagem, efetuouse uma análise de contrastes para detectar possíveis diferenças entre as médias de grupos de tratamentos. Esta análise mostrou que não houve diferença estatisticamente significativa entre os tratamentos testemunha (sem $\mathrm{Ca}$ ) e a calagem, provavelmente devido ao aumento da saturação de bases do tratamento testemunha causado pela liberação de cátions da matéria orgânica utilizada no substrato. A aplicação de $\mathrm{Ca}$ aumentou $26 \%$ em peso e $21 \%$ em número de frutos por metro quadrado em relação a não aplicação de cálcio. Estes

Tabela 1. Produção de frutos de melão Híbrido "Galileo", em cultivo protegido. Brasília, Embrapa Hortaliças, 2002.

\begin{tabular}{lccc}
\hline \multirow{2}{*}{ Tratamentos } & \multicolumn{2}{c}{ Frutos comerciais } & Peso médio \\
\cline { 2 - 3 } & $\mathbf{k g ~ m}^{-2}$ & $\mathbf{n}^{\mathbf{0}} \mathbf{~ m}^{-2}$ & $\mathbf{( g )}$ \\
\hline Testemunha & 2,11 & 2,78 & 767 \\
Calagem & 2,32 & 2,87 & 805 \\
Fertirrigação: Nitrato de cálcio & 2,77 & 3,33 & 830 \\
Fertirrigação: Cálcio tamponado & 2,64 & 3,61 & 732 \\
Fertirrigação: Cálcio quelatizado & 2,70 & 3,52 & 770 \\
Fertirrigação: Cloreto de cálcio & 2,89 & 3,61 & 805 \\
Teste F & $\mathrm{ns}$ & $\mathrm{ns}$ & $\mathrm{ns}$ \\
\hline C.V.(\%) & 18,91 & 17,54 & 8,45 \\
\hline Contrastes & & & $\mathrm{ns}$ \\
Testemunha x Calagem & $\mathrm{ns}$ & $*$ & $\mathrm{~ns}$ \\
Testemunha x Cálcio & $*$ & $* *$ & $\mathrm{~ns}$ \\
Testemunha x Fertirrigação & $* *$ & $*$ & $\mathrm{~ns}$ \\
Calagem x Fertirrigação & $\mathrm{ns}$ & & \\
\hline
\end{tabular}

*, **, e ns, significativo $(\mathrm{p}=0,05)$ ou $(\mathrm{p}=0,01)$ e não significativo, respectivamente.

Tabela 2. Concentração de cálcio em folhas de plantas de melão "Galileo" cultivado em vaso aos 55 e 91 dias após o transplantio (DAT). Brasília, Embrapa Hortaliças, 2002

\begin{tabular}{|c|c|c|}
\hline Tratamentos & 55 DAT $\left(\mathrm{g} \mathrm{kg}^{-1}\right)$ & 91 DAT $\left(\mathrm{g} \mathrm{kg}^{-1}\right)$ \\
\hline Testemunha & 12,29 & $8,54 \mathrm{~b}$ \\
\hline Calagem & 8,60 & $12,35 \mathrm{ab}$ \\
\hline Fertirrigação: Nitrato de cálcio & 11,14 & $12,22 \mathrm{~b}$ \\
\hline Fertirrigação: Cálcio tamponado & 10,35 & $15,02 \mathrm{a}$ \\
\hline Fertirrigação: Cálcio quelatizado & 10,89 & 13,59 a \\
\hline Fertirrigação: Cloreto de cálcio & 14,64 & 14,99 a \\
\hline C.V.(\%) & 27,58 & 26,94 \\
\hline Teste $\mathrm{F}$ & ns & * \\
\hline
\end{tabular}

*, e ns, significativo $(\mathrm{p}=0,05)$ e não significativo, respectivamente. Médias seguidas de letras iguais nas colunas não diferem estatisticamente pelo teste de Duncan.

resultados mostraram o efeito benéfico da aplicação de cálcio em pré-plantio pela calagem e/ou fertirrigação com $\mathrm{Ca}$ em solos com saturação de bases (V\%) abaixo de $70 \%$. Isto deve provavelmente ao aumento da disponibilidade de $\mathrm{Ca}$, do $\mathrm{pH}$ do solo e da melhoria das condições para absorção dos outros nutrientes.

A análise de contrastes também mostrou que a média dos tratamentos fertirrigados com cálcio diferiram $(\mathrm{p}<0,01)$ da sua não aplicação (testemunha) para as variáveis peso e número de frutos comerciais por metro quadrado. A produtividade foi $30 \%$ e o número dos frutos comerciais foi $27 \%$ maior na fertirrigação (Tabela 1).

A média do número de frutos comerciais dos tratamentos fertirrigados com cálcio e calagem foi $23 \%$ maior $(3,52$ frutos $\mathrm{m}^{-2}$ ) que no tratamento com calagem $\left(2,87\right.$ frutos $\left.\mathrm{m}^{-2}\right)$, indicando uma maior eficiência da fertirrigação com cálcio. Provavelmente, porque sendo o Ca de difícil translocação na planta (Poovaiah, 1985) e ser absorvido predominantemente pelo fluxo de massa, se acumula nas partes onde ocorrem as maiores taxas de transpiração, como as folhas. $\mathrm{Na}$ fase de grande demanda por $\mathrm{Ca}$, como na fase produtiva, haveria dificuldades para a translocação de Ca das folhas para regiões de rápido crescimento, como as regiões meristemáticas e os frutos, e desta maneira o contínuo suprimento de $\mathrm{Ca}$ às plantas na fertirrigação é o mais eficiente.

Os tratamentos fertirrigados com nitrato de cálcio e cloreto de cálcio proporcionaram maior rentabilidade (relação entre lucro e custo de produção), que foi respectivamente de 1,18 e 1,16; enquanto que os tratamentos com cálcio tamponado e cálcio quelatizado apresen- 
Tabela 3. Concentração média dos macro e micronutrientes nas folhas de plantas de melão "Galileo" cultivado em vaso aos 55 e 91 DAT. Brasília, Embrapa Hortaliças, 2002.

\begin{tabular}{|c|c|c|c|c|c|c|c|c|c|c|}
\hline \multirow{2}{*}{ DAT } & $\mathrm{Mg}$ & $\mathbf{N}$ & $\mathrm{K}$ & $\mathbf{P}$ & S & $\mathrm{Cu}$ & $\mathrm{Zn}$ & $\mathrm{Fe}$ & Mn & B \\
\hline & \multicolumn{5}{|c|}{$\mathbf{g ~ k g}^{-1}$} & \multicolumn{5}{|c|}{$\mathrm{mg} \mathrm{kg}^{-1}$} \\
\hline 55 & 2,57 & 44,98 & 21,81 & 4,53 & 5,75 & 0,63 & 6,43 & 14,97 & 34,39 & 65,04 \\
\hline 91 & 3,41 & 30,90 & 13,07 & 4,36 & 7,54 & 0,76 & 6,61 & 10,61 & 21,61 & 57,80 \\
\hline
\end{tabular}

taram rentabilidade menor $(0,53$ e 0,74 , respectivamente).

As concentrações de Ca encontradas aos 55 DAT e aos 91 DAT nas folhas de meloeiro (Tabela 2) foram inferiores às consideradas normais por Belfort et al., (1986). Entretanto, apresentaram concentração de cálcio dentro dos níveis considerados adequados (10-20 g. $\mathrm{kg}^{-1}$ ) por Locascio (1993), exceto o tratamento calagem aos 55 DAT e testemunha aos 91 DAT. Essa baixa concentração ocorreu, provavelmente, pela redução observado do sistema radicular das plantas cultivadas em vaso.

A média dos dados de concentração do cálcio nas folhas aos 91 DAT nos tratamentos onde este nutriente foi aplicado em fertirrigação foi $13 \%$ maior que o tratamento onde o cálcio foi aplicado somente na calagem. Isto mostrou que o cálcio aplicado na forma de fontes solúveis em fertirrigação, foi absorvido pelas plantas mais prontamente e mais eficientemente que o cálcio aplicado somente sob a forma de calcário devido a sua baixa solubilidade nesta fonte.

Nas tabelas 2 e 3 observa-se a seqüência decrescente de concentração dos macronutrientes; N, K, Ca, S, P e $\mathrm{Mg}$ mostrando também que o cálcio é um dos nutrientes de maior requerimento para o melão tipo Gália, híbrido Galileo cultivado nestas condições. Apesar de alguma variação ao longo do tempo, as concentrações de $\mathrm{N}, \mathrm{P}$ e $\mathrm{Mg}$ encontradas estavam dentro da faixa considerada adequada para a cultura de melão Gália, enquanto que o $\mathrm{K}$ estaria abaixo dos valores considerados normais segundo Rincon et al. (1998).

Os teores de micronutrientes (Tabela 3 ) nas folhas de melão foram inferiores aos valores considerados adequados (Locascio, 1993; Martinez et al., 1999). Alguns sintomas visuais de deficiência dos micronutrientes foram observados para valores abaixo de 1,$2 ; 11,1 ; 17,7$;
30,0 $\mathrm{mg} \mathrm{kg}^{-1}$ de $\mathrm{Cu}, \mathrm{Zn}$, Fe e Mn respectivamente (dados não apresentados). Existe a necessidade de realizar novos experimentos para definir os níveis críticos de micronutrientes para este tipo de melão nas condições de solo e clima de cerrados.

Não houve diferença $(p>0,05)$ para os teores de espessura da polpa (média de 2,91 cm), firmeza (média de 6,57 N), teor de sólidos solúveis (média de 11,28), acidez total titulável (média de 8,62 ) e relação Brix/ATT (média de $1,54)$. Estes valores foram de uma certa forma diferentes dos resultados obtidos por outros autores. Os valores médios de espessura foram inferiores aos valores encontrados por Menezes (1996) mas superiores aos valores encontrados por Artés et al. (1993) e por Pádua et al. (2001). Os teores médios para acidez total titulável (ATT) em todos tratamentos foram superiores ao encontrado por Artés et al. (1993) e os de firmeza foram inferiores aos de Souza et al. (2001). Tais divergências são devido, provavelmente, às diferenças de época, clima, manejo e sistema de plantio e cultivar, bem como ao avançado estágio de maturação dos frutos utilizados. O teor de sólidos solúveis totais é um dos fatores mais estudados e utilizados como critério de qualidade comercial. Neste trabalho os valores de sólidos solúveis encontrados ( ${ }^{\circ}$ Brix $>9 \%$ ) estão dentro do padrão ótimo para comercialização no mercado interno, que prefere frutos doces (Gonçalves et al., 1996).

Conclui-se que há a necessidade de aplicação de cálcio no meloeiro sob cultivo protegido para solos com saturação de base abaixo de $70 \%$ e que a calagem mais a fertirrigação com $\mathrm{Ca}$ foi mais efetiva que só a calagem. O uso do nitrato ou cloreto de $\mathrm{Ca}$ em fertirrigação apresentaram maior rentabilidade que a calagem, fertirrigação com $\mathrm{Ca}$ tamponado ou Ca quelatizado.

\section{LITERATURA CITADA}

ANDRADE, R.J. GONTIJO, G.M. Fertirrigação em Hortaliças. ( $1^{\mathrm{a}}$ aproximação de fertirrigação). Recomendação Técnica. 5 p. 1999. EMATER DF. Não publicada.

ARTÉS, F.; ESCRICHE, A.J.; MARTINEZ, J. A.; MARIN, J.G. Quality factors in four varieties of melons (Cucumis melo L.) Journal of Food Quality. v.16, n.2, p.91-100. 1993.

BAR-YOSEF, B. Advances in Fertigation. Advances in Agronomy, New York, v.65, p.1-77, 1999.

BELFORT, C.C.; HAAG, H.; MATSUMOTO, T.; CARMELLO, Q.A.C.; SANTOS, J.W.C. Nutrição mineral de hortaliças. LXX. Acumulação de matéria seca e recrutamento de macronutrientes pelo melão (Cucumis melo L. Cv. Valenciano Amarelo CAC) cultivado em Latossolo Vermelho Amarelo, em Presidente Venceslau, SP. Anais da ESALQ, Piracicaba, v.43, p.159-218, 1986.

BRANDÃO FILHO, J.U.T.; VASCONCELLOS, M.A.S.; A cultura do meloeiro. In: GOTO; TIVELLI, S.W. Produção de hortaliças em ambiente protegido: condições subtropicais. São Paulo: UNESP, 1998. p.161-193.

CANATO, G.H.D; BARBOSA, J.C.; CECÍLIO FILHO, A.B. Concentração de macro e micronutrientes em melão rendilhado cultivado em casa de vegetação. Horticultura Brasileira, Brasília, v.19, suplemento CD-ROM, julho 2001.

CANTÓN, J.M.R., El cultivo del melón en hidroponia. In: FERNANDEZ, M.F.; GOMEZ, I.M.C. (Ed.) Cultivos sin suelo II. Almería: Dirección General de Investigación y Formación Agraria de la Junta de Andalucía, 1999. p.535-561. CARRIJO, O.A.; MAROUELLI, W.A.; SILVA, W.L.C.; MORETTI, C.L.; SILVA, H.R.; FARIA, E.C.D. Fontes de nitrogênio para fertirrigação do meloeiro em cultivo protegido. Horticultura Brasileira, Brasília, v.19, suplemento CD-ROM, 2001.

FILGUEIRAS, H.A.C.; MENEZES, J.B.; ALVES, R.E.; COSTA, F.V.; PEREIRA, L.S.E.; GOMES JR., J. Colheita e manuseio pós-colheita. In: ALVES, R.E. (Org.). Melão pós-colheita. Fortaleza: EMBRAPA Agroindústria Tropical, 2000. p.23-43.

GONÇALVES, F.C.; MENEZES, J.B.; ALVES, R.E. Vida útil pós-colheita de melão Piel del sapo armazenamento em condições ambiente. Horticultura Brasileira. Brasília, v.14, n.1, p.49 - 52, 1996.

HERNANDEZ, C.; ASO, P.J. Fertilization of melon in greenhouses in Tucuman. Avance Agroindustrial, San Miguel de Tucumán, v.12, n.14, p.3-4, 1991.

LESTER, G.E.; Calcium alters senescence rate of postharvest muskmelon fruit disk. Postharvest Biology and Technology, v.7, p.91-96, 1996.

LOCASCIO, S. J. Cucurbits: Cucumber, muskmelon, and watermelon. In: BENNETT, W.F. Nutrient deficiencies and toxicities in crop plants. Saint Paul: APS PRESS, 1993. p.123-30.

MALLICK, M.F.R.; MASUI, M.; ISHIDA, A.; NUKAIA, A. Respiration and ethylene production in muskmelons in relation to nitrogen and calcium nutrition. Journal of the Japanese Society Horticultural Science, v.52, n.4, p.429-433, 1984. 
MARTINEZ, H.E.P., CARVALHO, J.G.; SOUZA, R.B.; Diagnose foliar. Recomendações para o uso de corretivos e fertilizantes em Minas Gerais: $5^{\mathrm{a}}$ aproximação. Viçosa: Comissão de Fertilidade do Solo do Estado de Minas Gerais, 1999. p.143-168. MENEZES, J.B. Qualidade pós-colheita de melão tipo Gália durante a maturação e o armazenamento. Lavras: UFLA, 1996, 157 p. (Tese doutorado)

MIYAZAMA, M.; PAVAN, M.A.; MURAOKA, T.; CARMO, C.A.F.S.; MELLO, W.J. Análises químicas de tecido vegetal. In: SILVA, F.C. $M a$ nual de análises químicas de solos, plantas e fertilizantes. Embrapa Solos, Embrapa Informática Agropecuária. Brasília: Embrapa Comunicação para transferência de tecnologia, 1999.370 p. PÁDUA, J.G.; BRAZ, L.T.; GUSMÃO, S.A.L.; GUSMÃO, M.T.A. Qualidade de frutos de melão rendilhado sob cultivo hidropônico nas condições de verão e inverno. Horticultura Brasileira, Brasília, v. 19, suplemento CD-Rom, julho, 2001.
PEREIRA, A.J. Produção e qualidade de melão amarelo submetido a pulverizações com duas fontes de cálcio. 1997.57 p. (Tese mestrado). UFLA, Lavras, MG.

PEREIRA, A.J.; SOUZA, R.J. Recomendação para adubação de melão para Minas Gerais. In RIBEIRO, A.C.; GUIMARÃES, P.T.C.; ALVAREZ, V.H., ed. Recomendações para o uso de corretivos e fertilizantes em Minas Gerais- $5^{\mathrm{a}}$ aproximação, 1999. p.193-194.

PERRIN, R.K.; WINKELMANN, D.L.; MOSCARDI, E.R.; ANDERSON, J.R. Formulacion de recomendaciones a partir de dados agronomicos. México: Centro Internacional de Mejoramiento de Maiz y trigo. 1976. P 54. (Folheto de Información $\mathrm{n}^{\mathrm{o}} 27$ ).

POOVAIAH, B.W. Role of calcium and calmodulin in plant growth and development. HortScience, v.20, n.3, p.347-351, 1985.
RINCON, L.S.; SAEZ, J.S.; PEREZ, J.A.C.; PELLICER, C.; GOMEZ, M.D.L. Crecimiento y absorción de nutrientes del melón bajo invernadero. Investigación Agraria: Producción Protección Vegetales. La Alberca, Murcia, v.13, n.1-2, p.111-120, 1998.

SILVA, J.R. Efeito do equilíbrio catiônico do solo na produção e qualidade de frutos de melão. 2000. 57 p. (Tese mestrado). Escola de Agronomia da UFC, Fortaleza, CE.

SILVA, H.R.: MAROUELLI, W.A.; SILVA, W.L.C.; SILVA, R.A.; OLIVEIRA, L.A.; RODRIGUES, A.G.; SOUZA, A.F.; MAENO, P. Cultivo do meloeiro para o Norte de Minas Gerais. Brasília: Embrapa Hortaliças, 2000. 24 p. (Circular Técnica, 20).

SOUZA, P.A.; MENEZES, J.B.; COSTA, F.B.; GUIMARÃES, A.A.; SIMÕES, A.N.; MENDONCA, F.V.S. Armazenamento refrigerado de melão Gália "Galileu". sob condições de atmosfera modificada. Horticultura Brasileira. Brasília, v.19, suplemento CD-Rom, julho, 2001. 